\title{
Effective Adsorption of Reactive Black 5 onto Hybrid Hexadecylamine Impregnated Chitosan-Powdered Activated Carbon Beads
}

\author{
Mohammadtaghi Vakili ${ }^{1}$, Haider M. Zwain ${ }^{2} \mathbb{D}$, Amin Mojiri ${ }^{3, * \mathbb{D}}$, Wei Wang ${ }^{4}$, \\ Fatemeh Gholami ${ }^{5}$, Zahra Gholami ${ }^{6}$, Abdulmoseen S. Giwa ${ }^{1}$, Baozhen Wang ${ }^{1}$, \\ Giovanni Cagnetta ${ }^{7}$ (D) and Babak Salamatinia ${ }^{8}$
}

1 Green Intelligence Environmental School, Yangtze Normal University, Chongqing 408100, China; mvakili1981@yahoo.com (M.V.); giwasegun25@yahoo.com (A.S.G.); 20170076@yznu.cn (B.W.)

2 College of Water Resources Engineering, Al-Qasim Green University, Al-Qasim Province, Babylon 51013, Iraq; haider.zwain@wrec.uoqasim.edu.iq

3 Department of Civil and Environmental Engineering, Graduate School of Advanced Science and Engineering, Hiroshima University, Higashihiroshima 739-8527, Japan

4 State Key Laboratory of Plateau Ecology and Agriculture, Qinghai University, Xi'ning 810016, Qinghai Province, China; weiwang@qhu.edu.cn

5 New Technologies-Research Centre, University of West Bohemia, 30100 Plzeň, Czech Republic; gholami@ntc.zcu.cz

6 Unipetrol Centre of Research and Education, a.s, Areál Chempark 2838, Záluží 1, 43670 Litvínov, Czech Republic; zgholami@gmail.com

7 State Key Joint Laboratory of Environment Simulation and Pollution Control, Beijing Key Laboratory for Emerging Organic Contaminants Control, School of Environment, Tsinghua University, Beijing 100084, China; gcagnetta@mail.tsinghua.edu.cn

8 Discipline of Chemical Engineering, School of Engineering, Monash University, Jalan Lagoon Selatan, Bandar Sunway, Selangor 47500, Malaysia; babak.salamatinia@monash.edu

* Correspondence: amin.mojiri@gmail.com

Received: 13 July 2020; Accepted: 6 August 2020; Published: 9 August 2020

\begin{abstract}
In this study, hexadecylamine (HDA) impregnated chitosan-powder activated carbon (Ct-PAC) composite beads were successfully prepared and applied to adsorption of the anionic dye reactive black 5 (RB5) in aqueous solution. The Ct-PAC-HDA beads synthesized with $0.2 \mathrm{~g}$ powdered activated carbon (PAC) and $0.04 \mathrm{~g}$ HDA showed the highest dye removal efficiency. The prepared beads were characterized using Fourier-transform infrared spectroscopy (FTIR) and scanning electron microscopy (SEM). Various adsorption parameters, i.e., adsorbent dosage, $\mathrm{pH}$, and contact time, which affect the adsorption performance, were studied in a series of batch experiments. The obtained adsorption data were found to be better represented by Freundlich $\left(R^{2}=0.994\right)$ and pseudo-second-order $\left(R^{2}=0.994\right)$ models. Moreover, it was ascertained that the adsorption of RB5 onto Ct-PAC-HDA beads is pH-dependent, and the maximum Langmuir adsorption capacity $(666.97 \mathrm{mg} / \mathrm{g})$ was observed at $\mathrm{pH} 4$. It was also proved that Ct-PAC-HDA beads were regenerable for repeated use in the adsorption process.
\end{abstract}

Keywords: chitosan; powder activated carbon; hexadecylamine; hybrid adsorbent; regeneration

\section{Introduction}

In recent years, the unprecedented development of industrial and urban activities has led to a significant increase in wastewater discharge into the environment, often contaminated with harmful organic pollutants (e.g., dyestuffs). Therefore, the separation/elimination of these pollutants from water 
sources is a goal that must be accomplished to ensure human and environmental safety [1]. Due to their high toxicity, chemical stability, and low biodegradability, dyes are a class of pollutants that are raising increasing concern, since they cause severe problems to aquatic life and human beings [2]. In particular, reactive dyes are being widely used in dyeing processes because of their notable properties such as ease of application, high color fastness, bright colors, and a wide shade gamut from black to vibrant, brilliant shades [3-5]. However, a low degree of fixation to the fabrics, high water solubility, and poor adsorption ability are the main reasons for the intense color of the effluents that contain such kind of dyes [6]. Discharge of such type of wastewater into the environment is known to threaten the ecosystem due to high toxicity and reduction of sunlight penetration into the water, thus affecting aquatic biota living functions [7]. Hence, the elimination of reactive dyes from aqueous effluents is a necessary action that must be taken to prevent further spread in the environment and adverse effects. To date, different treatment techniques have been developed for this aim. Among them, adsorption processes have received much attention from researchers due to its cost-effectiveness, simplicity, and high efficiency [8]. The properties of materials that are used as adsorbents are key factors for adsorption efficiency [9]. In recent years, the development of adsorbents obtained from non-toxic, sustainable, and renewable natural resources (e.g., biopolymers) has intensified [10].

Chitosan $(\mathrm{Ct})$ is a suitable material in this area because of its non-toxicity, abundance, availability, biodegradability, and ability to adsorb organic pollutants (including reactive dyes). This biopolymer is a multifunctional cationic biodegradable polysaccharide produced by deacetylation of chitin. Because of the presence of several functional groups (in particular, $\mathrm{NH}_{2}$ and $\mathrm{OH}$ ) on the $\mathrm{Ct}$ backbone, this material has a high potential affinity to dyes. However, low porosity, small surface area, scarce acid stability, and limited adsorption capacity preclude its application at full-scale for wastewater treatment [11]. Also, raw Ct is available in powder form, thus it is not easy to separate from aqueous solutions after the adsorption process. Its crystallinity and hydrophobicity are features that reduce the liquid-to-solid mass transfer rate and induce column clogging and high pressure drops, thereby resulting in high operation costs [12]. Modification of $\mathrm{Ct}$ is a feasible way to overcome these limitations and improve its adsorption performance [13].

Among such modification methods, preparation of $\mathrm{Ct}$-based hybrid adsorbents has received significant attention and is considered as one of the most efficient ways to improve Ct properties. The use of hybrid adsorbents is not only cost-effective, environmentally friendly, and safe, but also can reduce shortcomings of constituent materials and consequently increase their value for practical applications [14]. Hybridized adsorbents obtained from Ct and carbonaceous materials can fulfill these criteria and, therefore, they have attracted the attention of researchers as potential materials for green technology development. The combination of $\mathrm{Ct}$ and carbonaceous materials is an efficient method to enhance its thermochemical and mechanical properties. Additionally, carbonaceous materials can enhance functionality and pore properties of $\mathrm{Ct}$ and thus improve its adsorption capability [15]. It was proved by Yadaei et al. [16] that Ct-activated carbon hybrid adsorbent possesses favorable strength and porous structure. The development of hybrid adsorbents obtained from $\mathrm{Ct}$ and carbonaceous materials has been reported in some studies $[17,18]$. Carbonaceous materials are extensively applied in the purification of water as efficient adsorbents owing to their high functional group's number, high porosity, and large surface area [19]. Among them, powdered activated carbon (PAC) has been widely used in water treatment to control odor, color, and taste because of its remarkable adsorption potentiality, fast adsorption kinetic, availability, and low cost [20]. Despite such noteworthy characteristics, PAC suffers from some critical drawbacks that limit its application: small particle size and powder form, as well as difficulties in regeneration and separation from aqueous solutions [21].

The immobilization of PAC particles in some kind of matrix is one way to overcome the problems mentioned above. Preparation of Ct-PAC hybrid adsorbent can combine the advantages of $\mathrm{Ct}$ and PAC, showing strong adsorption capacity for different kinds of pollutants. This study combines PAC with $\mathrm{Ct}$ in a bead shape, thus achieving its stabilization, prevention of carbon leaching, and improved separability of the prepared adsorbent from the solution. However, the PAC would cover the surface of 
chitosan and occupy its active functional groups. It may negatively affect the dye removal efficiency of the prepared hybrid adsorbent. Therefore, increasing the number of functional groups (mainly amino groups) through chemical modification using different types of modification agents will improve the adsorption properties of the prepared hybrid adsorbent. Impregnation with cationic surfactants is an appropriate strategy leading to an increase in the functional groups and positive charge density of the adsorbent.

The present study aims to further enhance the adsorption capability of the prepared Ct-PAC hybrid beads using a cationic surfactant. Hexadecylamine (HDA) is a cationic surfactant possessing a positively charged hydrophilic group $\left(\mathrm{NH}_{2}\right)$ that can be applied to increase the number of amino groups already present in $\mathrm{Ct}$, as well as to augment the positive charge of the synthesized adsorbent [22]. Therefore, the main objectives of this study were the preparation of Ct-PAC hybrid beads, as well as using HDA for increasing the functional groups and cationicity of the material for adsorption of reactive dye from water. To the best of our knowledge, such modification has not been reported in the literature. Thus, there is a necessity in understanding the behavior of this combination as an effective adsorbent for improved reactive dye removal. In the present research, the anionic dye reactive black 5 (RB5) is utilized as a model pollutant molecule to assess the adsorption performance of the prepared hybrid adsorbent. The effect of preparation conditions (i.e., PAC and HDA concentration) and adsorption parameters (i.e., $\mathrm{pH}$ of dye solution, adsorbent dosage, and contact time) on RB5 adsorption behavior is investigated. Kinetic and isotherm studies also are conducted to reveal the adsorption behavior of RB5 onto the prepared adsorbent. Moreover, the regeneration of the Ct-PAC-HDA adsorbent is assessed.

\section{Materials and Methods}

\subsection{Chemicals and Materials}

Chitosan (medium-molecular-weight $75-85 \%$ deacetylation) and hexadecylamine $\left(\mathrm{C}_{16} \mathrm{H}_{35} \mathrm{~N}, 98 \%\right)$ were purchased from Sigma-Aldrich (Beijing, China). RB5, sodium hydroxide $(\mathrm{NaOH})$, hydrochloric acid $(\mathrm{HCl})$ and acetic acid $\left(\mathrm{CH}_{3} \mathrm{COOH}\right)$ were all supplied by Beijing Chemical Works. A commercial PAC was obtained from Sinopharm Chemical Reagent Co., Ltd. (Shanghai, China). All chemicals in the present study were analytical grade. The chemicals were used directly without further purification.

\subsection{Preparation of Adsorbent}

For the preparation of the Ct-PAC solution, Ct solution was mixed with PAC, as described previously by Vakili et al. [10]. Briefly, Ct flakes ( $2 \mathrm{~g}$ ) were dissolved into $100 \mathrm{~mL}$ acetic acid solution $(3 \% \mathrm{v} / \mathrm{v})$ under continuous stirring $(400 \mathrm{rpm})$ at room temperature $\left(25^{\circ} \mathrm{C}\right)$ for $5 \mathrm{~h}$. Then, the desired concentration of PAC $(0.10,0.2,0.30,0.40$, and $0.50 \mathrm{~g})$ was poured into the $\mathrm{Ct}$ solution and stirred for $3 \mathrm{~h}$ to study the effect of PAC concentration. Preparation of the HDA impregnated Ct-PAC beads was conducted following the conditions reported by Vakili et al. [22]. Concisely, the desired amount of HDA was mixed with the Ct-PAC solution at $400 \mathrm{rpm}$ and $50^{\circ} \mathrm{C}$ for $6 \mathrm{~h}$. In the Ct-PAC solution, the concentration of HDA was varied from 0.02 to $0.1 \mathrm{~g}$. Then the prepared Ct-PAC-HDA solution was poured dropwise into a $500 \mathrm{~mL}$ precipitation solution $(\mathrm{NaOH}, 2 \mathrm{M})$, followed by gentle stirring overnight. For removing the residual $\mathrm{NaOH}$, the prepared $\mathrm{Ct}-\mathrm{PAC}-\mathrm{HDA}$ beads were washed several times using deionized water. Finally, all the beads were oven-dried at $60^{\circ} \mathrm{C}$ for $12 \mathrm{~h}$.

\subsection{Characterization}

For studying the functional groups of the prepared adsorbent, Fourier-transform infrared spectroscopy (FTIR) spectra of the Ct-PAC-HDA beads were obtained at $500-4000 \mathrm{~cm}^{-1}$ using a Thermo Nicolet NEXUS (Thermofisher, Waltham, MA, USA). The surface morphological features of the adsorbent were assessed employing scanning electron microscopy (SEM) using a Phenom Prox, Phenom-world, Holland. 


\subsection{Adsorption and Desorption Experiments}

Batch adsorption experiments were designed to study RB5 adsorption onto Ct-PAC-HDA beads. A desired mass of the adsorbent was mixed with an RB5 solution $(200 \mathrm{~mL})$ in a $250 \mathrm{~mL}$ Erlenmeyer flask. Then, the mixture was shaken using an orbital shaker at $150 \mathrm{rpm}$ at room temperature $\left(25^{\circ} \mathrm{C}\right)$ for $24 \mathrm{~h}$. The optimum $\mathrm{pH}$ was determined by adding the prepared beads $(20 \mathrm{mg})$ into $200 \mathrm{~mL}$ ( $50 \mathrm{mg} / \mathrm{L}$ ) RB5 solution at different $\mathrm{pH}$ values ranging from 2 to 10 . The solution $\mathrm{pH}$ was adjusted to the desired values using $\mathrm{NaOH}(0.1 \mathrm{M})$ and $\mathrm{HCl}(0.1 \mathrm{M})$ solutions. The effect of adsorbent dosage on the removal of RB5 was studied in the RB5 concentration range between 10 and $50 \mathrm{~g} / \mathrm{L}$ at $100 \mathrm{mg} / \mathrm{L}$. All of the experiments in this study were conducted in triplicate. For quantifying the residual RB5 concentration, after the adsorption process, the spectrophotometric technique was applied using a UV-Vis spectrophotometer (Hach DR 5000, Germany) at a wavelength of $597 \mathrm{~nm}$. The adsorption capacity and removal efficiency of the Ct-PAC-HDA beads were calculated using the following equations:

$$
\begin{aligned}
& \mathrm{q}_{\mathrm{e}}=\left(\left(\mathrm{C}_{0}-\mathrm{C}_{\mathrm{e}}\right) \times \mathrm{V}\right) / \mathrm{W} \\
& \mathrm{RE}=\left(\mathrm{C}_{0}-\mathrm{C}_{\mathrm{e}} / \mathrm{C}_{0}\right) \times 100
\end{aligned}
$$

$\mathrm{q}_{\mathrm{e}}=$ Adsorption capacity $(\mathrm{mg} / \mathrm{g})$

RE $=$ Removal efficiency $(\%)$

$\mathrm{C}_{0}=$ Initial RB5 concentration $(\mathrm{mg} / \mathrm{L})$

$\mathrm{C}_{\mathrm{e}}=$ Equilibrium RB5 concentration $(\mathrm{mg} / \mathrm{L})$

$\mathrm{V}=\mathrm{RB} 5$ solution volume $(\mathrm{L})$

$\mathrm{W}=$ Adsorbent mass $(\mathrm{g})$

The effect of time and the adsorption rates of the dye were evaluated through adsorption kinetic experiments, performed at an RB5 concentration of $200 \mathrm{mg} / \mathrm{L}$. The obtained results were assessed based on pseudo-first-order (PFO; Equation (3)) and pseudo-second-order (PSO; Equation (4)) kinetic models.

$$
\begin{gathered}
q_{t}=q_{e}\left(1-e^{-k t}\right) \\
q_{t}=\left(q_{e} v_{0} t\right) /\left(q_{e}+v_{0} t\right)
\end{gathered}
$$

$\mathrm{q}_{\mathrm{t}}=\mathrm{RB} 5$ adsorption at time $\mathrm{t}(\mathrm{mg} / \mathrm{g})$

$\mathrm{q}_{\mathrm{e}}=\mathrm{RB} 5$ adsorption at equilibrium $(\mathrm{mg} / \mathrm{g})$

$\mathrm{k}=\mathrm{PFO}$ rate constant $(1 / \mathrm{min})$

$\mathrm{v}_{0}=\mathrm{PFO} / \mathrm{PSO}$ rate constant $(\mathrm{g} / \mathrm{mg} / \mathrm{min})$

$\mathrm{t}=$ time $(\mathrm{min})$

To assess the transmission of adsorbate from solution phase to the adsorbent phase at equilibrium condition, adsorption isotherm experiments were performed at six RB5 concentrations (20,40, 80, 120, 160 and $200 \mathrm{mg} / \mathrm{L}$ ) at $25^{\circ} \mathrm{C}$ and with contact time of $24 \mathrm{~h}$. Two adsorption isotherms, i.e., the Langmuir (Equation (5)) and Freundlich (Equation (6)), were applied to express the isotherm data.

$$
\begin{gathered}
\mathrm{q}_{\mathrm{e}}=\left(\mathrm{q}_{\mathrm{m}} \mathrm{C}_{\mathrm{e}} \mathrm{b}\right) /\left(1+\mathrm{bC}_{\mathrm{e}}\right) \\
\mathrm{q}_{\mathrm{e}}=\mathrm{K}_{\mathrm{F}} \mathrm{C}_{\mathrm{e}}{ }^{(1 / n)}
\end{gathered}
$$

$\mathrm{q}_{\mathrm{t}}=$ Maximum adsorption capacity of the Ct-PAC-HDA beads $(\mathrm{mg} / \mathrm{g})$

$\mathrm{q}_{\mathrm{m}}=$ Maximum adsorption capacity of the adsorbent $(\mathrm{mg} / \mathrm{g})$

$\mathrm{C}_{\mathrm{e}}=\mathrm{RB} 5$ equilibrium concentration $(\mathrm{mg} / \mathrm{L})$

$\mathrm{B}=$ Affinity of Ct-PAC-HDA beads towards RB5 (L/g)

$\mathrm{K}_{\mathrm{F}}=$ Freundlich constant $(\mathrm{mg} / \mathrm{g})$ 
$\mathrm{N}=$ Adsorption intensity

The reusability of the adsorbent was evaluated by mixing $30 \mathrm{mg}$ of Ct-PAC-HDA beads with $200 \mathrm{~mL}$ of RB5 solution $(100 \mathrm{mg} / \mathrm{L})$ at $\mathrm{pH} 4$ for $24 \mathrm{~h}$. Afterward, saturated beads were separated and regenerated using $0.1 \mathrm{M}$ of $\mathrm{NaOH}$ solution. Then, the regenerated adsorbents were applied again in the next adsorption experiment. The adsorption and desorption cycle was repeated until the RB5 adsorption capacity of the adsorbent dropped significantly, to study the regeneration performance of the adsorbent.

\section{Results and Discussion}

\subsection{Effects of the Reaction Conditions}

Figure 1a presents the impact of PAC concentration on the adsorption of RB5 on Ct-PAC beads. PAC had a positive effect on the RB5 adsorption performance of the Ct-PAC beads. Increasing the amount of PAC into the Ct solution up to $0.20 \mathrm{~g}$ increased RB5 removal from a solution with RB5 concentration of $20 \mathrm{mg} / \mathrm{L}$, to $78.91 \%$. This enhancement could be caused by the increase in the beads' surface area by the addition of PAC, which resulted in a broader availability of functional groups for adsorption of RB5 molecules [23]. However, a further increase in PAC concentration (up to $0.40 \mathrm{~g}$ ) led to a decrease in the removal of RB5, to $67.29 \%$. The presence of a high amount of PAC likely caused the collapse of the structure and, consequently, a decrease of accessibility to functional groups in the $\mathrm{Ct}$-PAC beads [24]. Moreover, at higher PAC concentration $(>0.40 \mathrm{~g})$, the added dropwise Ct-PAC solution into the precipitation solution could not solidify to form beads. This might be due to the low entanglement rate and low polymerization of $\mathrm{Ct}$ in the Ct-PAC solution, caused by the existence of a high amount of PAC in Ct solution [25].
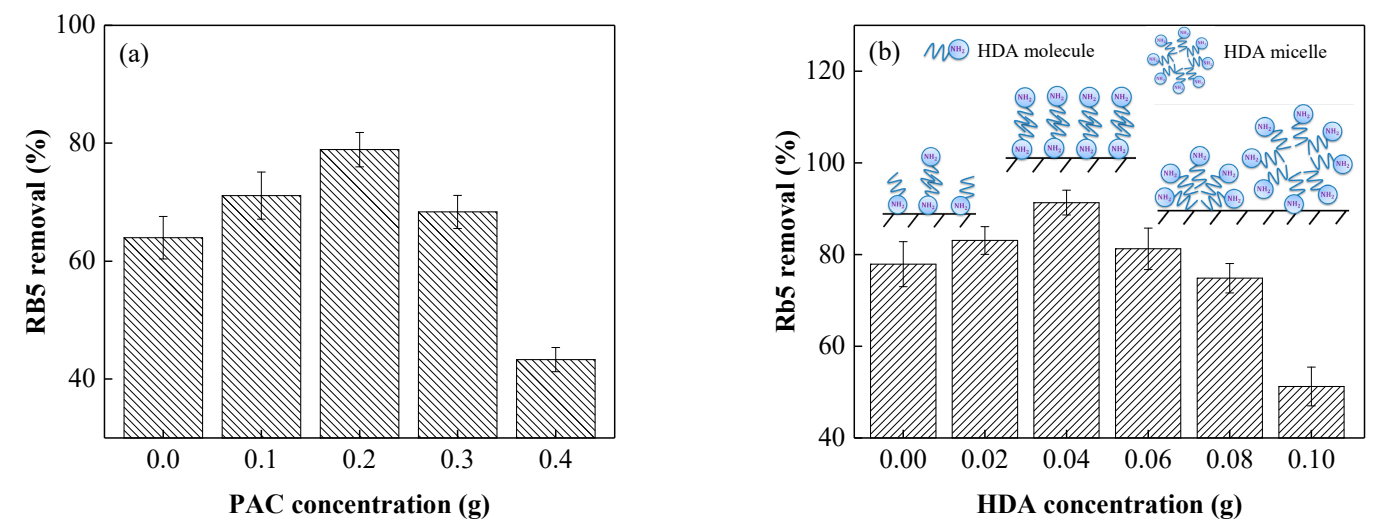

Figure 1. Effect of (a) powdered activated carbon (PAC) and (b) hexadecylamine (HDA) concentrations on the adsorption efficiency of reactive black 5 (RB5) onto the adsorbents ( $20 \mathrm{mg}$ of beads, $200 \mathrm{~mL}$ of $20 \mathrm{mg} / \mathrm{L}$ of $\mathrm{RB} 5, \mathrm{pH}=6,25^{\circ} \mathrm{C}, 24 \mathrm{~h}$ ).

The effect of HDA concentration on the RB5 adsorption performance of the Ct-PAC-HDA beads was investigated, and results are displayed in Figure 1b. As noticed, the RB5 removal efficiency of the beads is initially enhanced by an increase in the amount of HDA (up to a concentration of $0.04 \mathrm{~g}$ ). Then, a significant adsorption capacity decrease, along with the rise in the HDA concentration, is observed. Specifically, the optimal RB5 removal percentage was $91.32 \%$. This phenomenon is likely due to the increase in the number of amine groups, as well as the positive charge of the beads attributed to the presence of HDA molecules. This led to a rise in the adsorbate-adsorbent electrostatic interactions and, thus, the higher RB5 adsorption capacity of the beads [26]. However, at higher HDA concentrations $(>0.04 \mathrm{~g})$, the decrease in the RB5 adsorption onto the Ct-PAC-HDA beads can be attributed to the self-aggregation of HDA molecules, by forming micelles at high concentration. These micelles can 
block the pores on the beads and decrease the accessibility of functional groups to RB5 molecules (Figure 1b) [22].

\subsection{Adsorbent Characterization}

Relevant surface functional groups on Ct-PAC beads (before and after impregnation) were verified by FTIR analysis, and the spectral data are presented in Figure 2. In the Ct-PAC beads, the main overlapping area of stretching vibrations of amine and hydroxyl groups appears as a strong and broadband in the region of $3070-3800 \mathrm{~cm}^{-1}$. The smaller peak at $2913 \mathrm{~cm}^{-1}$ is attributed to the stretching vibration of the $\mathrm{CH}_{2}$ groups [27]. Moreover, peaks at 1635, 1378, and $1012 \mathrm{~cm}^{-1}$ could be assigned to amide II band, $\mathrm{N}-\mathrm{H}$ bending, alcoholic $\mathrm{C}-\mathrm{O}$, and $\mathrm{C}-\mathrm{N}$ stretching, respectively. Compared to $\mathrm{Ct}-\mathrm{PAC}$, the FTIR spectrum of Ct-PAC-HDA presents wavenumber shift of several peaks, as well as changes in intensity. After HDA impregnation, the peaks at 3266, 2913, 1635, 1373, $985 \mathrm{~cm}^{-1}$ were shifted to higher frequencies: $3415,2915,1646,1380,1000 \mathrm{~cm}^{-1}$, respectively. These changes might be owed to the overlap of stretching bands of amine and hydroxyl groups of $\mathrm{HDA}, \mathrm{CH}$, and PAC. These findings suggest that Ct-PAC beads chemically adsorb HDA through interaction between the amine group of the HDA molecule and the hydroxyl group on the Ct-PAC beads [22].

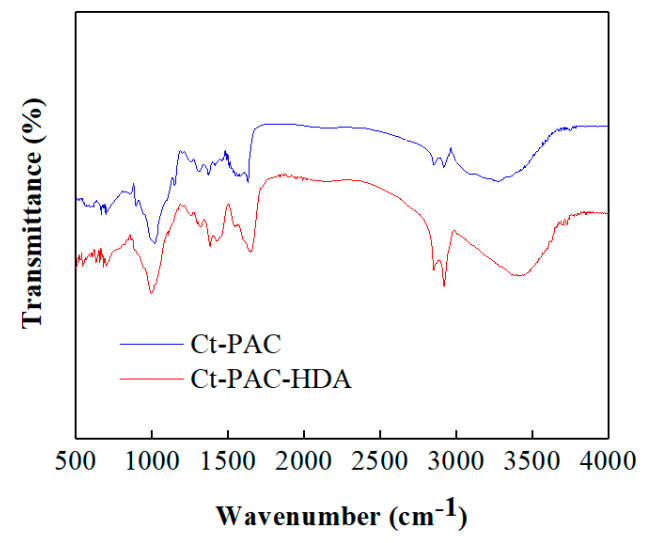

Figure 2. Fourier-transform infrared spectroscopy (FTIR) spectra of Ct-PAC and Ct-PAC-HDA beads.

The surface morphology of the prepared beads is shown in Figure 3. In both before and after impregnation, the adsorbents display a heterogeneous and uniform surface, which is favorable for adsorption of RB5. However, the Ct-PAC-HDA bead (Figure 3b) shows a more uneven, rough, and heterogeneous surface than that of the Ct-PAC bead (Figure 3a). These properties could be attributed to the presence of HDA in the structure of the Ct-PAC beads, which in the end may increase the contact area, number/availability of functional groups, and adsorption capacity of the beads.

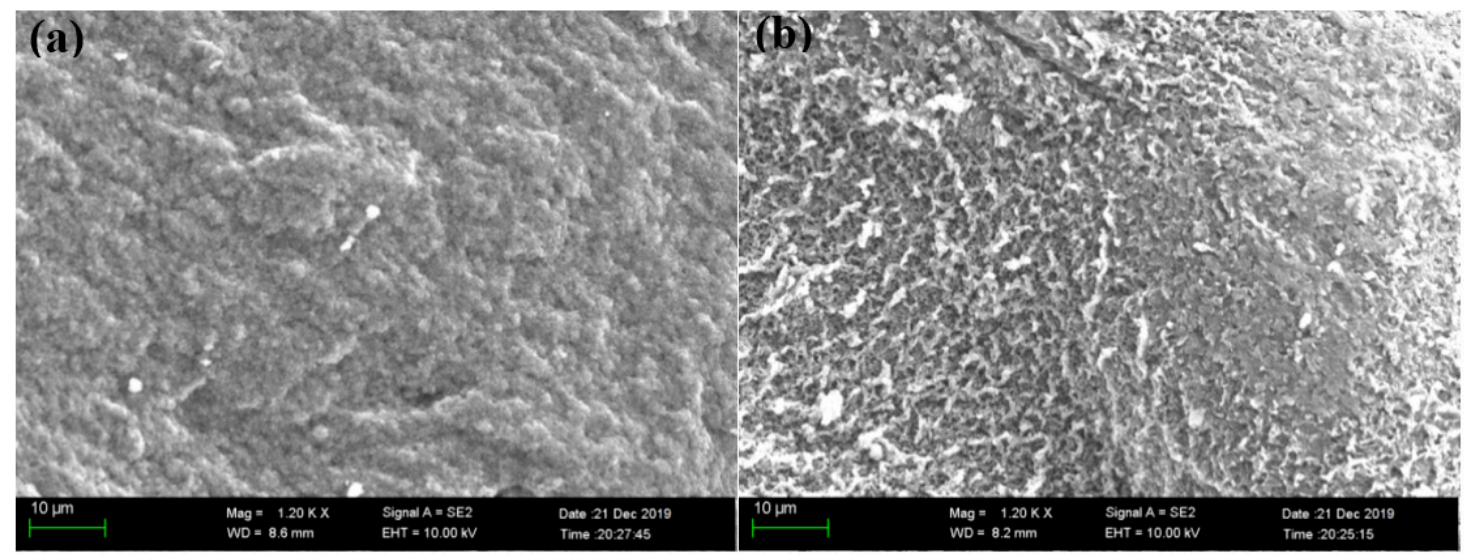

Figure 3. Scanning electron microscopy (SEM) images of (a) Ct-PAC and (b) Ct-PAC-HDA beads. 


\subsection{RB5 Adsorption Experiments}

\subsubsection{Effect of Adsorbent Dosage on RB5 Removal}

The impact of the quantity of Ct-PAC-HDA beads on the removal of RB5 was analyzed, and the results are illustrated in Figure 4. The adsorption capacity increased from $105.78 \mathrm{mg} / \mathrm{g}$ to $140.9 \mathrm{mg} / \mathrm{g}$ for an increase in the amount of Ct-PAC-HDA beads from 10 to $30 \mathrm{~g} / \mathrm{L}$. Obviously, at higher adsorbent doses, increasing the surface area, as well as augmenting the number of accessible, functional groups, leads to a higher RB5 adsorption rate [28]. However, a further increase in the adsorbent quantity ( $>30 \mathrm{~g} / \mathrm{L}$ ) reduced the RB5 adsorption capacity of Ct-PAC-HDA beads. The reduction in adsorption capacity could be due to the conglomeration and interaction of adsorbent particles resulting from a high concentration of adsorbent. This phenomenon likely reduces the total surface area and increases the diffusional path length, leading to the unsaturation of the functional groups through the adsorption process $[29,30]$. Thus, based on the maximum dye removal efficiency and minimum adsorbent mass, the amount of Ct-PAC-HDA beads was fixed at $30 \mathrm{~g} / \mathrm{L}$.

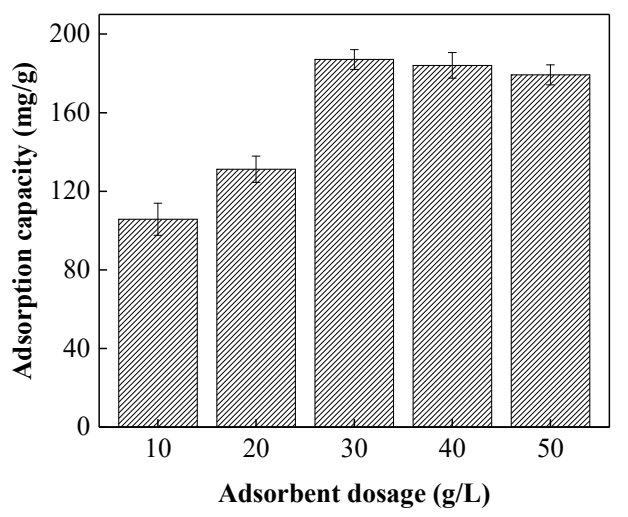

Figure 4. Effect of adsorbent dosage on the adsorption of RB5.

\subsubsection{Effect of $\mathrm{pH}$ on RB5 Removal}

The adsorption of an anionic dye onto a cationic adsorbent is generally governed by the number of charged functional groups on the adsorbent surface, which is highly dependent on its environment's $\mathrm{pH}$ [31]. Therefore, the effect of the solution $\mathrm{pH}$ on the removal of RB5 using Ct-PAC-HDA was studied, and the results are presented in Figure 5a. It was observed that RB5 adsorption of Ct-PAC-HDA beads was significantly dependent on this parameter. RB5 adsorption was higher at acidic conditions, with the maximum $\mathrm{RB} 5$ uptake $(187.08 \mathrm{mg} / \mathrm{g})$ obtained at $\mathrm{pH}=4$. Around this $\mathrm{pH}$ value, the presence of appropriate quantities of protons $\left(\mathrm{H}^{+}\right)$induces protonation of amine groups on the Ct-PAC-HDA beads $\left(\mathrm{NH}_{3}{ }^{+}\right)$and changes the charge of the beads to markedly positive values [32]. On the other hand, in the aqueous phase the sulfonic groups $\left(-\mathrm{SO}_{3} \mathrm{H}\right)$ in the $\mathrm{RB} 5$ molecules are converted to their anionic form (i.e., sulfonate group, $\left(-\mathrm{SO}_{3}{ }^{-}\right)$) because the first dissociation acidity constant of sulfonic groups in reactive dyes is very low $(\mathrm{pKa} \approx 2)$ [33]. These phenomena result in higher RB5 uptake due to the enhanced electrostatic interactions between positively charged beads and negatively charged anionic dye molecules (Figure 5b).

$$
\begin{gathered}
\text { RB5- } \mathrm{SO}_{3} \mathrm{H}+\mathrm{H}_{2} \mathrm{O} \rightarrow \mathrm{RB}_{-}-\mathrm{SO}_{3}{ }^{-} \\
\text {Adsorbent- } \mathrm{NH}_{2}+\mathrm{H}^{+} \rightarrow \text { Adsorbent- } \mathrm{NH}_{3}{ }^{+} \\
\text {Adsorbent- } \mathrm{NH}_{3}{ }^{+}+\mathrm{RB}_{-}-\mathrm{SO}_{3}{ }^{-} \rightarrow \text { Adsorbent- } \mathrm{NH}_{3}{ }^{+}{ }_{3} \mathrm{SO}-\mathrm{RB} 5
\end{gathered}
$$

Nevertheless, at very low $\mathrm{pH}$ values $(\mathrm{pH}<4)$, the uptake of $\mathrm{RB} 5$ decreased. This is attributed to the protonation of higher amounts of amine groups, and thus inducing repulsion among Ct-PAC-HDA components, and possibly dissolution of $\mathrm{Ct}$ because of glycosidic bond hydrolyzation [34]. Moreover, at very acidic $\mathrm{pH}$ values, which are closer to $-\mathrm{SO}_{3} \mathrm{H} \mathrm{pK}_{\mathrm{a}}$, the sulfonic groups are shifted toward their 
protonated form, thus augmenting the positive charge of $\mathrm{RB} 5$ by conversion of anionic $-\mathrm{SO}_{3}{ }^{-}$groups to $-\mathrm{SO}_{3} \mathrm{H}$. In the low-acidic/basic range $(\mathrm{pH}>6)$, the Ct-PAC-HDA beads showed weak $\mathrm{RB} 5$ adsorption capacity. At high $\mathrm{pH}$ values, massive deprotonation of the amine groups on the beads results in the repulsion of anionic RB5 molecules [35].
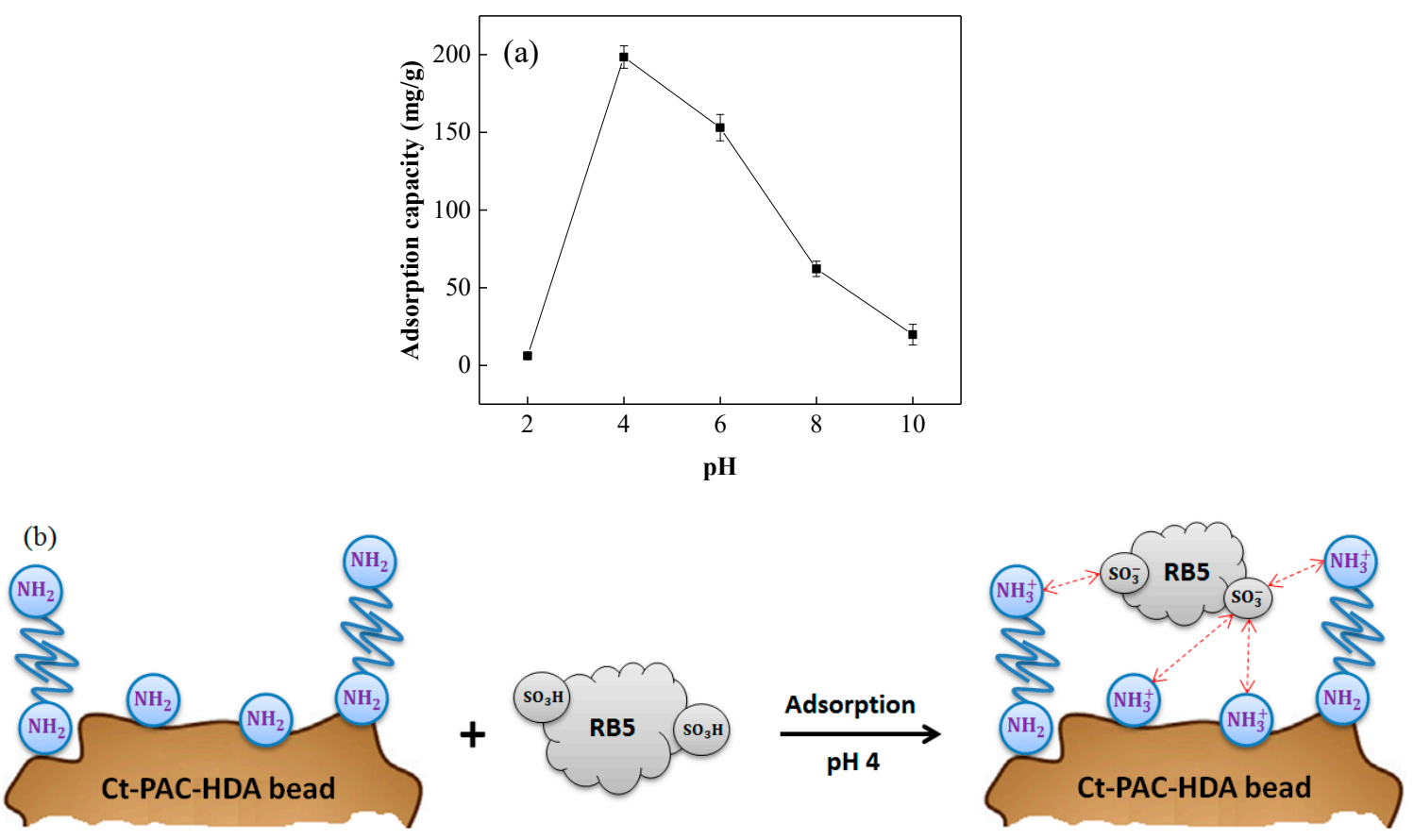

Figure 5. (a) Effect of $\mathrm{pH}$ on the adsorption of RB5 using Ct-PAC-HDA beads ( $30 \mathrm{mg}$ of beads, $200 \mathrm{~mL}$ of $50 \mathrm{mg} / \mathrm{L}$ of RB5, $25^{\circ} \mathrm{C}, 24 \mathrm{~h}$ ) and (b) schematic diagram of the RB5 adsorption mechanism by Ct-PAC-HDA beads.

\subsubsection{Kinetic Study of RB5 Adsorption}

For estimating the removal efficiency of an adsorbent, the equilibrium time for adsorption of adsorbate is considered as one of the most critical parameters. Hence, the variation of RB5 adsorption onto the Ct-PAC-HDA beads as a function of contact time was studied (Figure 6). Results revealed that by increasing contact time, the adsorption capacity of the Ct-PAC-HDA beads increased and reached the maximum level within $10 \mathrm{~h}$. Afterward, prolongation of the contact time led to a reduction of adsorption rate until it remained almost stable after $15 \mathrm{~h}$ (equilibrium time). The high RB5 removal rate at an initial $240 \mathrm{~min}$ is likely owed to a large number of unoccupied/free functional groups on the adsorbent surface. Then, gradual occupation and saturation of functional groups on the Ct-PAC-HDA beads by RB5 molecules result in a decrease in the adsorption rate until the equilibrium is reached [36]. 


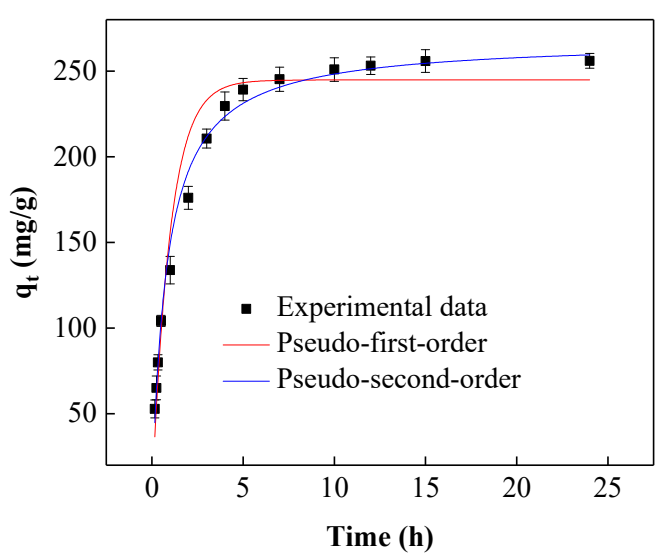

Figure 6. Adsorption kinetics of RB5 onto Ct-PAC-HDA beads ( $30 \mathrm{mg}$ of beads, $200 \mathrm{~mL}$ of $200 \mathrm{mg} / \mathrm{L}$ of $\mathrm{RB} 5, \mathrm{pH}=4,25^{\circ} \mathrm{C}, 24 \mathrm{~h}$ ).

The obtained adsorption data were modeled in PFO and PSO kinetic models, and the calculated parameters are presented in Table 1. By comparing the kinetic data, it is found that RB5 adsorption is described better by the PSO kinetic model. The correlation coefficient $\left(R^{2}\right)$ and the Chi-square $\left(\chi^{2}\right)$ values of the PSO are higher and lower, respectively, than those of the PFO model. Furthermore, the calculated adsorption capacity by the PSO model $(260.12 \mathrm{mg} / \mathrm{g})$ fits well with the experimental adsorption capacity $(256.01 \mathrm{mg} / \mathrm{g})$. These results suggest that adsorption of RB5 onto the Ct-PAC-HDA beads is mainly controlled by chemisorption [37].

Table 1. The constants obtained from the kinetic parameters for RB5 adsorption onto Ct-PAC-HDA beads.

\begin{tabular}{cc}
\hline Kinetic parameters & Values \\
\hline Pseudo-first-order & \\
$\mathrm{C}_{0}(\mathrm{mg} / \mathrm{L})$ & 200 \\
$\mathrm{q}_{\mathrm{e}}(\mathrm{mg} / \mathrm{g})$ & $246.81 \pm 5.939$ \\
$\mathrm{q}_{\mathrm{cal}}(\mathrm{mg} / \mathrm{g})$ & $1.009 \pm 0.0930$ \\
$\mathrm{k}(1 / \mathrm{min})$ & 7.57 \\
$\chi^{2}$ & 0.968 \\
$\mathrm{R}^{2}$ & -0.366 \\
Slope & 5.123 \\
Intercept & 200 \\
Pseudo-second-order & 256.01 \\
$\mathrm{C}_{0}(\mathrm{mg} / \mathrm{L})$ & $260.13 \pm 3.851$ \\
$\mathrm{q}_{\mathrm{e}}(\mathrm{mg} / \mathrm{g})$ & $335.24 \pm 18.29$ \\
$\mathrm{q}_{\mathrm{cal}}(\mathrm{mg} / \mathrm{g})$ & 1.26 \\
$\mathrm{~V}_{0}(\mathrm{~g} / \mathrm{mg} / \mathrm{min})$ & 0.994 \\
$\chi^{2}$ & 0.004 \\
$\mathrm{R}^{2}$ & 0.003 \\
Slope & \\
Intercept &
\end{tabular}

\subsubsection{Isotherm Study of RB5 Adsorption}

For investigating suitable conditions for the optimized application of the prepared adsorbent, as well as the study of the nature of RB5 adsorption on Ct-PAC-HDA beads, adsorption equilibrium results were fitted by Langmuir and Freundlich isotherm models (Figure 7). Calculated model parameters (Table 2) reveal that both isotherm models show a good fit with experimental data $\left(R^{2}>0.99\right)$. However, the Freundlich model represents a better fit for the experimental results (according to the higher $\mathrm{R}^{2}$ and lower $\chi^{2}$ estimated for the fitting of the Freundlich model, with respect 
to those of the Langmuir model). These findings suggest that the adsorption of RB5 onto the Ct-PAC-HDA beads was controlled by multilayer adsorption, where the functional groups on the external particle layers have a heterogeneous nature [38]. The calculated adsorption intensity $(n=1.3)$ indicates a strong interaction between RB5 and Ct-PAC-HDA beads (i.e., a favorable adsorption process) [39].

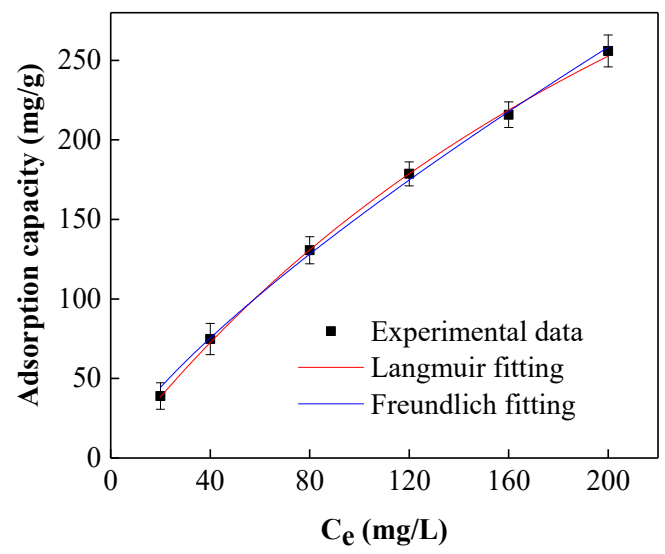

Figure 7. Adsorption isotherms of RB5 onto Ct-PAC-HDA beads ( $30 \mathrm{mg}$ of beads, $\mathrm{pH}=4,25^{\circ} \mathrm{C}, 24 \mathrm{~h}$ ).

Table 2. The constants obtained from the isotherm parameters for adsorption of RB5 onto Ct-PAC-HDA beads.

\begin{tabular}{cc}
\hline Isotherm parameters & Values \\
\hline Langmuir & \\
$\mathrm{q}_{\mathrm{m}}(\mathrm{mg} / \mathrm{g})$ & $666.97 \pm 38.14$ \\
$\mathrm{~b}(\mathrm{l} / \mathrm{mg})$ & 0.225 \\
$\chi^{2}$ & 0.997 \\
$\mathrm{R}^{2}$ & 0.002 \\
Slope & 0.201 \\
Intercept & \\
Freundlich & $4.48 \pm 0.495$ \\
$\mathrm{~K}_{\mathrm{F}}(\mathrm{mg} / \mathrm{g})$ & $1.3 \pm 0.038$ \\
$\mathrm{n}$ & 0.074 \\
$\chi^{2}$ & 0.999 \\
$\mathrm{R}^{2}$ & 0.686 \\
Slope & 2.279 \\
Intercept &
\end{tabular}

Moreover, a comparison of the maximum Langmuir adsorption capacity value of the adsorbent prepared in the present study with those of other adsorbing materials described in the literature suggests that Ct-PAC-HDA has relatively high RB5 adsorption capacity (Table 3). The adsorption capacity of Ct-PAC-HDA beads was found to be almost 1112 times higher than that achieved by using an Eichhornia crassipes/chitosan composite [39]. It showed 585 times higher capacity than macadamia seed husks [40] while performing 12 times better than the peanut hull [41]. The Ct-PAC-HDA outperformed the dolomite [42], activated carbon F400 [43], and polyethyleneimine/sodium dodecyl sulphate [44] by 8.20, 3.37, and 1.61 times better removals, respectively. A 33.10\% higher adsorption was observed with the developed beads as compared to the pine-fruit shell activated carbon [28]. Thereby, Ct-PAC-HDA beads might be an effective adsorbent for the elimination of reactive dyes from wastewaters with satisfactory adsorption capacity. 
Table 3. Comparison of the maximum RB5 adsorption capacity of different adsorbents.

\begin{tabular}{cccc}
\hline Adsorbent & $\mathbf{p H}$ & $\mathbf{q}_{\mathbf{m}} \mathbf{( \mathbf { m g } / \mathbf { g } )}$ & Ref. \\
\hline Eichhornia crassipes/chitosan composite & 3 & 0.60 & {$[39]$} \\
Macadamia seed husks & 3 & 1.14 & {$[40]$} \\
Fly ash & 7 & 7.18 & {$[45]$} \\
Edible fungi activated carbon & 2 & 19.6 & {$[46]$} \\
Peanut hull & 6.4 & 55.55 & {$[41]$} \\
Pine-fruit shell & 2 & 74.6 & {$[28]$} \\
Dolomite & 6.9 & 80.9 & {$[42]$} \\
Bone char & 5.2 & 160.0 & {$[43]$} \\
Activated carbon F400 & 5.2 & 197.5 & {$[43]$} \\
Chitosan/polyamide nanofibers & 1 & 198.60 & {$[47]$} \\
Polyacrylamide/silica nanoporous composite & 2 & 389.58 & {$[27]$} \\
Polyethyleneimine/sodium dodecyl sulphate & 4 & 413.23 & {$[44]$} \\
Bamboo activated carbon & 5.2 & 441.7 & {$[37]$} \\
Pine-fruit shell activated carbon & 6 & 446.2 & {$[28]$} \\
Ct-PAC-HDA beads & 4 & 666.97 & Present study \\
\hline
\end{tabular}

\subsection{Desorption and Reuse of Spent Ct-PAC-HDA Beads}

Reuse evaluation of adsorbent is very fundamental for potential full-scale application because it permits the assessment of the adsorbent capability to recover after a cycle of utilization (i.e., adsorptiondesorption). The regeneration minimizes the need for new absorbents, recovers resources, reduces the secondary waste, and decreases the process costs [48]. For assessing the reusability of the Ct-PAC-HDA beads, regeneration experiments were performed by repeating several adsorption-desorption cycles. According to Vakili et al. [49], the regeneration of chitosan-based adsorbents saturated with reactive dyes was successfully conducted by $\mathrm{NaOH}$ solution; therefore, it was selected as an eluent for the regeneration of RB5 loaded Ct-PAC-HDA beads. As can be seen in Figure 8, during the first five subsequent regeneration cycles, the RB5 adsorption capacity showed only a $6 \%$ loss. Such a reduction is possibly due to incomplete desorption of RB5 molecules. Afterward, adsorption capacity dropped to 46.59 at the tenth cycle ( $75 \%$ loss), which might be attributed to the saturation of functional groups on adsorbent [50].

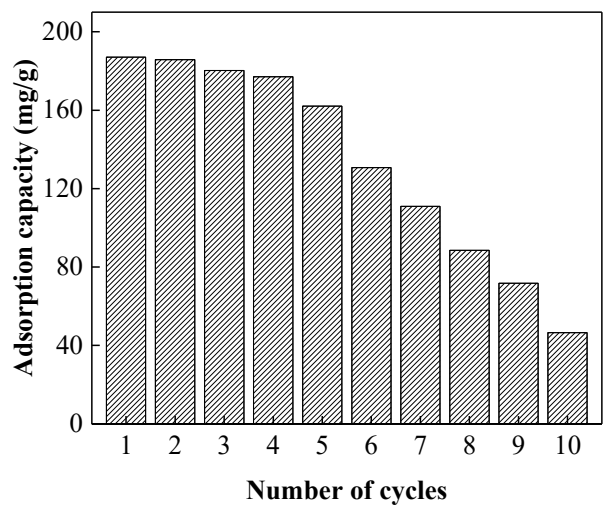

Figure 8. Effect of regeneration cycles on the RB5 adsorption capacity of Ct-PAC-HDA beads.

\section{Conclusions}

Ct-PAC-HDA beads were successfully prepared for the elimination of RB5 from aqueous solutions. The maximum enhancement in the adsorption performance of adsorbent was achieved using $0.04 \mathrm{~g}$ HDA and $0.2 \mathrm{~g}$ PAC. The removal of RB5 increased with decreasing $\mathrm{pH}$. The isotherm and kinetic study concluded that the adsorption data fitted better to the Freundlich and PSO models than the Langmuir and PFO models. The results suggested that the adsorption of RB5 onto the Ct-PAC-HDA 
beads was a chemisorption process that occurred on multilayer heterogeneous surfaces. The maximum RB5 adsorption capacity of Ct-PAC-HDA beads $(666.97 \mathrm{mg} / \mathrm{g})$ was obtained with $30 \mathrm{~g} / \mathrm{L}$ of adsorbent, at acidic condition ( $\mathrm{pH} 4$ ), $30 \mathrm{~g} / \mathrm{L}$ of adsorbent mass, and during $10 \mathrm{~h}$ (equilibrium time). Moreover, regeneration experiments demonstrated that the prepared beads have good reusability and can be regenerated at least 5 cycles without significant adsorption capacity loss. Generally, the results revealed the great potential of Ct-PAC-HDA as a promising adsorbent for the elimination of reactive dyes.

Author Contributions: Formal analysis, W.W. and B.W.; investigation, M.V.; methodology, F.G. and G.C.; software, Z.G.; supervision, A.M.; validation, A.S.G.; writing-review and editing, H.M.Z. and B.S. All authors have read and agreed to the published version of the manuscript.

Funding: The Yangtze Normal University supported this work.

Conflicts of Interest: The authors declare no conflict of interest.

\section{References}

1. Farraji, H.; Robinson, B.; Mohajeri, P.; Abedi, T. Phytoremediation: Green technology for improving aquatic and terrestrial environments. Nippon. J. Environ. Sci. 2020, 1, 1-30.

2. Vakili, M.; Rafatullah, M.; Salamatinia, B.; Abdullah, A.Z.; Ibrahim, M.H.; Tan, K.B.; Gholami, Z.; Amouzgar, P. Application of chitosan and its derivatives as adsorbents for dye removal from water and wastewater: A review. Carbohyd. Polym. 2014, 113, 115-130. [CrossRef] [PubMed]

3. Vakili, M.; Rafatullah, M.; Salamatinia, B.; Ibrahim, M.H.; Abdullah, A.Z. Elimination of reactive blue 4 from aqueous solutions using 3-aminopropyl triethoxysilane modified chitosan beads. Carbohyd. Polym. 2015, 132, 89-96. [CrossRef] [PubMed]

4. Homaeigohar, S. The nanosized dye adsorbents for water treatment. Nanomaterials 2020, 10, 1-19. [CrossRef] [PubMed]

5. Lewis, D.M. 9-The chemistry of reactive dyes and their application processes. In Handbook of Textile and Industrial Dyeing; Clark, M., Ed.; Woodhead Publishing: Sawston, UK, 2011; Volume 1, pp. 303-364.

6. Nabil, G.M.; El-Mallah, N.M.; Mahmoud, M.E. Enhanced decolorization of reactive black 5 dye by active carbon sorbent-immobilized-cationic surfactant (AC-CS). J. Ind. Eng. Chem. 2014, 20, 994-1002. [CrossRef]

7. Vakili, M.; Rafatullah, M.; Gholami, Z.; Farraji, H. Treatment of reactive dyes from water and wastewater through chitosan and its derivatives. Smart Mater. Waste Water Appl. 2016, 347-377. [CrossRef]

8. Vakili, M.; Rafatullah, M.; Ibrahim, M.H.; Abdullah, A.Z.; Gholami, Z.; Salamatinia, B. Enhancing reactive blue 4 adsorption through chemical modification of chitosan with hexadecylamine and 3-aminopropyl triethoxysilane. J. Water Process. Eng. 2017, 15, 49-54. [CrossRef]

9. Vakili, M.; Rafatullah, M.; Ibrahim, M.H.; Abdullah, A.Z.; Salamatinia, B.; Gholami, Z. Oil palm biomass as an adsorbent for heavy metals. Rev. Environ. Contam. T 2014, 232, 61-88.

10. Vakili, M.; Mojiri, A.; Kindaichi, T.; Cagnetta, G.; Yuan, J.; Wang, B.; Giwa, A.S. Cross-linked chitosan/zeolite as a fixed-bed column for organic micropollutants removal from aqueous solution, optimization with RSM and artificial neural network. J. Environ. 2019, 250, 109434. [CrossRef]

11. Vakili, M.; Amouzgar, P.; Cagnetta, G.; Wang, B.; Guo, X.; Mojiri, A.; Zeimaran, E.; Salamatinia, B. Ultrasound-Assisted Preparation of Chitosan/Nano-Activated Carbon Composite Beads Aminated with (3-Aminopropyl) Triethoxysilane for Adsorption of Acetaminophen from Aqueous Solutions. Polymers 2019, 11, 1701. [CrossRef]

12. Vakili, M.; Mojiri, A.; Zwain, H.M.; Yuan, J.; Giwa, A.S.; Wang, W.; Gholami, F.; Guo, X.; Cagnetta, G.; Yu, G. Effect of beading parameters on cross-linked chitosan adsorptive properties. React. Funct. Polym. 2019, 144, 104354. [CrossRef]

13. Qiu, W.; Vakili, M.; Cagnetta, G.; Huang, J.; Yu, G. Effect of high energy ball milling on organic pollutant adsorption properties of chitosan. Int. J. Biol. Macromol. 2020, 148, 543-549. [CrossRef] [PubMed]

14. Lan, W.; He, L.; Liu, Y. Preparation and Properties of Sodium Carboxymethyl Cellulose/Sodium Alginate/Chitosan Composite Film. Coatings 2018, 8, 1-17. [CrossRef]

15. Ahmed, M.J.; Hameed, B.H.; Hummadi, E.H. Review on recent progress in chitosan/chitin-carbonaceous material composites for the adsorption of water pollutants. Carbohyd. Polym. 2020, 247, 116690. [CrossRef] 
16. Yadaei, H.; Beyki, M.H.; Shemirani, F.; Nouroozi, S. Ferrofluid mediated chitosan@mesoporous carbon nanohybrid for green adsorption/preconcentration of toxic Cd(II): Modeling, kinetic and isotherm study. React. Funct. Polym. 2018, 122, 85-97. [CrossRef]

17. Arumugam, T.K.; Krishnamoorthy, P.; Rajagopalan, N.R.; Nanthini, S.; Vasudevan, D. Removal of malachite green from aqueous solutions using a modified chitosan composite. Int. J. Biol. Macromol. 2019, 128, 655-664. [CrossRef]

18. Yan, M.; Huang, W.; Li, Z. Chitosan cross-linked graphene oxide/lignosulfonate composite aerogel for enhanced adsorption of methylene blue in water. Int. J. Biol. Macromol. 2019, 136, 927-935. [CrossRef]

19. Vakili, M.; Rafatullah, M.; Salamatinia, B.; Ibrahim, M.H.; Ismail, N.; Abdullah, A.Z. Adsorption Studies of Methyl Tert-butyl Ether from Environment. Sep. Purif. Rev. 2017, 46, 273-290. [CrossRef]

20. Lv, S.; Zhou, Z.; Xue, M.; Zhang, X.; Yang, Z. Adsorption characteristics of reactive blue 81 by powdered activated carbon: Role of the calcium content. J. Water Process. Eng. 2020, 36, 101247. [CrossRef]

21. Zhou, J.; Ma, F.; Guo, H. Adsorption behavior of tetracycline from aqueous solution on ferroferric oxide nanoparticles assisted powdered activated carbon. Chem. Eng. J. 2020, 384, 123290. [CrossRef]

22. Vakili, M.; Rafatullah, M.; Ibrahim, M.H.; Abdullah, A.Z.; Salamatinia, B.; Gholami, Z. Chitosan hydrogel beads impregnated with hexadecylamine for improved reactive blue 4 adsorption. Carbohyd. Polym. 2016, 137, 139-146. [CrossRef] [PubMed]

23. Amouzgar, P.; Vakili, M.; Chan, E.-S.; Salamatinia, B. Effects of beading parameters for development of chitosan-nano-activated carbon biocomposite for acetaminophen elimination from aqueous sources. Environ. Eng. Sci. 2017, 34, 805-815. [CrossRef]

24. Mahaninia, M.H.; Wilson, L.D. Phosphate uptake studies of cross-linked chitosan bead materials. J. Colloid Interface Sci. 2017, 485, 201-212. [CrossRef] [PubMed]

25. Chatterjee, S.; Lee, D.S.; Lee, M.W.; Woo, S.H. Enhanced adsorption of congo red from aqueous solutions by chitosan hydrogel beads impregnated with cetyl trimethyl ammonium bromide. Bioresour. Technol. 2009, 100, 2803-2809. [CrossRef]

26. Sutirman, Z.A.; Sanagi, M.M.; Abd Karim, K.J.; Ibrahim, W.A.W.; Jume, B.H. Equilibrium, kinetic and mechanism studies of $\mathrm{Cu}$ (II) and Cd (II) ions adsorption by modified chitosan beads. Int. J. Biol. Macromol. 2018, 116, 255-263. [CrossRef] [PubMed]

27. Nematollahzadeh, A.; Shojaei, A.; Karimi, M. Chemically modified organic/inorganic nanoporous composite particles for the adsorption of reactive black 5 from aqueous solution. React. Funct. Polym. 2015, 86, 7-15. [CrossRef]

28. Cardoso, N.F.; Pinto, R.B.; Lima, E.C.; Calvete, T.; Amavisca, C.V.; Royer, B.; Cunha, M.L.; Fernandes, T.H.M.; Pinto, I.S. Removal of remazol black B textile dye from aqueous solution by adsorption. Desalination 2011, 269, 92-103. [CrossRef]

29. Banerjee, S.; Chattopadhyaya, M.C. Adsorption characteristics for the removal of a toxic dye, tartrazine from aqueous solutions by a low cost agricultural by-product. Arab. J. Chem. 2017, 10, S1629-S1638. [CrossRef]

30. Subramaniam, R.; Kumar Ponnusamy, S. Novel adsorbent from agricultural waste (cashew NUT shell) for methylene blue dye removal: Optimization by response surface methodology. Water Resour. Ind. 2015, 11, 64-70. [CrossRef]

31. Huang, R.; Liu, Q.; Huo, J.; Yang, B. Adsorption of methyl orange onto protonated cross-linked chitosan. Arab. J. Chem. 2017, 10, 24-32. [CrossRef]

32. El-Bindary, M.; El-Deen, I.; Shoair, A. Removal of anionic dye from aqueous solution using magnetic sodium alginate beads. J. Mater. Environ. Sci. 2019, 10, 604-617.

33. Wong, S.; Ghafar, N.A.; Ngadi, N.; Razmi, F.A.; Inuwa, I.M.; Mat, R.; Amin, N.A.S. Effective removal of anionic textile dyes using adsorbent synthesized from coffee waste. Sci. Rep. 2020, 10, 2928. [CrossRef] [PubMed]

34. Kasaai, M.R.; Arul, J.; Charlet, G. Fragmentation of Chitosan by Acids. Sci. World J. 2013, $2013,508540$. [CrossRef] [PubMed]

35. Batool, F.; Akbar, J.; Iqbal, S.; Noreen, S.; Bukhari, S.N.A. Study of Isothermal, Kinetic, and Thermodynamic Parameters for Adsorption of Cadmium: An Overview of Linear and Nonlinear Approach and Error Analysis. Bioinorg. Chem. Appl. 2018, 2018, 3463724. [CrossRef] [PubMed] 
36. Dehmani, Y.; Alrashdi, A.A.; Lgaz, H.; Lamhasni, T.; Abouarnadasse, S.; Chung, I.-M. Removal of phenol from aqueous solution by adsorption onto hematite ( $\alpha$-Fe2O3): Mechanism exploration from both experimental and theoretical studies. Arab. J. Chem. 2020, 13, 5474-5486. [CrossRef]

37. Mondal, M.; Manoli, K.; Ray, A.K. Removal of arsenic (III) from aqueous solution by concrete-based adsorbents. Can. J. Chem. Eng. 2020, 98, 353-359. [CrossRef]

38. Al-Senani, G.M.; Al-Kadhi, N.S. Studies on Adsorption of Fluorescein Dye from Aqueous Solutions Using Wild Herbs. Int. J. Anal. Chem. 2020, 2020, 8019274. [CrossRef]

39. El-Zawahry, M.M.; Abdelghaffar, F.; Abdelghaffar, R.A.; Hassabo, A.G. Equilibrium and kinetic models on the adsorption of Reactive Black 5 from aqueous solution using Eichhornia crassipes/chitosan composite. Carbohyd. Polym. 2016, 136, 507-515. [CrossRef]

40. Felista, M.M.; Wanyonyi, W.C.; Ongera, G. Adsorption of anionic dye (Reactive black 5) using macadamia seed Husks: Kinetics and equilibrium studies. Sci. Afr. 2020, 7, e00283. [CrossRef]

41. Tanyildizi, M.Ş. Modeling of adsorption isotherms and kinetics of reactive dye from aqueous solution by peanut hull. Chem. Eng. J. 2011, 168, 1234-1240. [CrossRef]

42. Ziane, S.; Bessaha, F.; Marouf-Khelifa, K.; Khelifa, A. Single and binary adsorption of reactive black 5 and Congo red on modified dolomite: Performance and mechanism. J. Mol. Liq. 2018, 249, 1245-1253. [CrossRef]

43. Ip, A.W.M.; Barford, J.P.; McKay, G. A comparative study on the kinetics and mechanisms of removal of Reactive Black 5 by adsorption onto activated carbons and bone char. Chem. Eng. J. 2010, 157, 434-442. [CrossRef]

44. Chatterjee, S.; Chatterjee, T.; Woo, S.H. Influence of the polyethyleneimine grafting on the adsorption capacity of chitosan beads for Reactive Black 5 from aqueous solutions. Chem. Eng. J. 2011, 166, 168-175. [CrossRef]

45. Eren, Z.; Acar, F.N. Equilibrium and kinetic mechanism for Reactive Black 5 sorption onto high lime Soma fly ash. J. Hazard. Mater. 2007, 143, 226-232. [CrossRef] [PubMed]

46. Xiao, H.; Peng, H.; Deng, S.; Yang, X.; Zhang, Y.; Li, Y. Preparation of activated carbon from edible fungi residue by microwave assisted $\mathrm{K}_{2} \mathrm{CO}_{3}$ activation-Application in reactive black 5 adsorption from aqueous solution. Bioresour. Technol. 2012, 111, 127-133. [CrossRef]

47. Li, Z.; Sellaoui, L.; Dotto, G.L.; Lamine, A.B.; Bonilla-Petriciolet, A.; Hanafy, H.; Belmabrouk, H.; Netto, M.S.; Erto, A. Interpretation of the adsorption mechanism of Reactive Black 5 and Ponceau 4R dyes on chitosan/polyamide nanofibers via advanced statistical physics model. J. Mol. Liq. 2019, 285, 165-170. [CrossRef]

48. Vakili, M.; Deng, S.; Cagnetta, G.; Wang, W.; Meng, P.; Liu, D.; Yu, G. Regeneration of chitosan-based adsorbents used in heavy metal adsorption: A review. Sep. Purif. Technol. 2019, 224, 373-387. [CrossRef]

49. Vakili, M.; Deng, S.; Shen, L.; Shan, D.; Liu, D.; Yu, G. Regeneration of chitosan-based adsorbents for eliminating dyes from aqueous solutions. Sep. Purif. Rev. 2019, 48, 1-13. [CrossRef]

50. Chen, A.-H.; Huang, Y.-Y. Adsorption of Remazol Black 5 from aqueous solution by the templated crosslinked-chitosans. J. Hazard. Mater. 2010, 177, 668-675. [CrossRef]

(C) 2020 by the authors. Licensee MDPI, Basel, Switzerland. This article is an open access article distributed under the terms and conditions of the Creative Commons Attribution (CC BY) license (http://creativecommons.org/licenses/by/4.0/). 